\title{
Preclinical development of a humanized neutralizing antibody targeting HGF
}

\author{
Hyori Kim ${ }^{1}$, Sung Hee Hong ${ }^{2,10}$, Jung Yong Kim², In-Chull Kim², Young-Whan Park ${ }^{2}$, Song-Jae Lee, \\ Seong-Won Song 3 , Jung Ju Kim ${ }^{3}$, Gunwoo Park ${ }^{4}$, Tae Min Kim, ${ }^{5,6}$, Yun-Hee Kim ${ }^{7,8}$, Jong Bae Park ${ }^{7}$, \\ Junho Chung ${ }^{6,9}$ and In-Hoo $\mathrm{Kim}^{7}$
}

Hepatocyte growth factor (HGF) and its receptor, cMET, play critical roles in cell proliferation, angiogenesis and invasion in a wide variety of cancers. We therefore examined the anti-tumor activity of the humanized monoclonal anti-HGF antibody, YYB-101, in nude mice bearing human glioblastoma xenografts as a single agent or in combination with temozolomide. HGF neutralization, The extracellular signal-related kinases 1 and 2 (ERK1/2) phosphorylation, and HGF-induced scattering were assessed in HGF-expressing cell lines treated with YYB-101. To support clinical development, we also evaluated the preclinical pharmacokinetics and toxicokinetics in cynomolgus monkeys, and human and cynomolgus monkey tissue was stained with YYB-101 to test tissue cross-reactivity. We found that YYB-101 inhibited cMET activation in vitro and suppressed tumor growth in the orthotopic mouse model of human glioblastoma. Combination treatment with YYB-101 and temozolomide decreased tumor growth and increased overall survival compared with the effects of either agent alone. Five cancer-related genes (TMEM119, FST, RSP03, ROS1 and NBL1) were overexpressed in YYB-101-treated mice that showed tumor regrowth. In the tissue cross-reactivity assay, critical cross-reactivity was not observed. The terminal elimination half-life was $\mathbf{2 1 . 7}$ days. Taken together, the in vitro and in vivo data demonstrated the anti-tumor efficacy of YYB-101, which appeared to be mediated by blocking the HGF/CMET interaction. The preclinical pharmacokinetics, toxicokinetics and tissue cross-reactivity data support the clinical development of YYB-101 for advanced cancer.

Experimental \& Molecular Medicine (2017) 49, e309; doi:10.1038/emm.2017.21; published online 24 March 2017

\section{INTRODUCTION}

Hepatocyte growth factor (HGF), also known as scatter factor, is a multifunctional cytokine composed of an amino-terminal domain and four kringle domains in the alpha chain $(54-65 \mathrm{kDa})$ and a serine protease homology domain in the beta chain $(31-35 \mathrm{kDa}) .{ }^{1}$ The binding of HGF to its receptor, cMET, activates intracellular signal transduction pathways that regulate cell proliferation, motility, invasion, angiogenesis, and anti-apoptosis. ${ }^{2,3}$ Thus, aberrant activation of the HGF/cMET pathway triggers growth and metastasis in a variety of human cancers. ${ }^{4,5}$ Upregulation of HGF and the overexpression and activation of cMET are observed in a number of human cancers such as breast, head and neck, lung, prostate, renal, colorectal, and hepatocellular as well as myeloma, glioblastoma

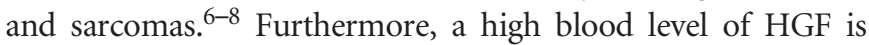
associated with poor prognosis in gastric and ovarian cancer. ${ }^{6,9}$ For example, HGF and cMET expression levels correlate with tumor invasiveness, metastasis, and overall survival in breast cancer $^{10-12}$ and with poor survival rates in non-small-cell lung cancer. ${ }^{13,14}$ Given that the interaction of HGF and cMET is involved in tumorigenesis and metastasis, both proteins are promising targets for therapeutic agents. HGF inhibitors bind

\footnotetext{
${ }^{1}$ Asan Institute for Life Sciences, Asan Medical Center, Songpa-gu, Seoul, Republic of Korea; ${ }^{2}$ National OncoVenture, National Cancer Center, Goyang-si, Gyeonggi-do, Republic of Korea; ${ }^{3}$ Yooyoung Central Research Institute, Yooyoung Pharmaceutical Co. Ltd., Guro-gu, Seoul, Republic of Korea; ${ }^{4}$ Research Institute, National Cancer Center, Goyang-si, Gyeonggi-do, Republic of Korea; ${ }^{5}$ Department of Internal Medicine, Seoul National University Hospital, Jongno-gu, Seoul, Republic of Korea; ${ }^{6}$ Cancer Research Institute, Seoul National University College of Medicine, Jongno-gu, Seoul, Republic of Korea; ${ }^{7}$ Graduate School of Cancer Science and Policy, National Cancer Center, Goyang-si, Gyeonggi-do, Republic of Korea; ${ }^{8}$ Research Institute, National Cancer Center, Goyang-si, Gyeonggi-do, Republic of Korea and ${ }^{9}$ Department of Biochemistry and Molecular Biology, Seoul National University College of Medicine, Jongno-gu, Seoul, Republic of Korea

${ }^{10}$ Current address: Handok Pharmaceutical Co. Ltd., 132 Teheran-Ro, Gangnam-Gu, Seoul 06235, Republic of Korea.

Correspondence: Dr J Chung, Department of Biochemistry and Molecular Biology, Seoul National University College of Medicine, 101 Daehag-ro, Jongno-gu, Seoul 03080, Republic of Korea.

E-mail: jjhchung@snu.ac.kr or junhochung@icloud.com

or Dr I-H Kim, Graduate School of Cancer Science and Policy, National Cancer Center, Goyang-si, Gyeonggi-do 10408, Republic of Korea.

E-mail: ikim@ncc.re.kr or inhookim@gmail.com
}

Received 8 December 2016; accepted 23 December 2016 
to HGF to prevent its interaction with cMET and the subsequent activation of the HGF/cMET pathway. We previously generated a rabbit-human antibody that effectively neutralizes the in vitro activity of HGF. ${ }^{15}$ In a colorectal cancer cell xenograft model, this antibody effectively suppressed innate irinotecan resistance induced by fibroblast-derived HGF. ${ }^{16}$

In this study, we tested a humanized version of the anti-HGF antibody (YYB101) using in vitro HGF neutralization assays and an orthotopic mouse model of human glioblastoma. We then carried out tissue cross-reactivity, pharmacokinetic, and toxicity studies of the monoclonal antibody (mAb) compliant with good laboratory practice. In this preclinical study, we evaluated the dose response of YYB-101 and compared the efficacy of YYB-101 alone versus combination therapy with YYB-101 and temozolomide (TMZ), the standard-of-care chemotherapy drug.

\section{MATERIALS AND METHODS ERK phosphorylation assay}

After a 24-h incubation in serum-free medium, human liver carcinoma HepG2 cells were treated for 5 min with 128 pM HGF (ProSpec, Rehovot, Israel) along with either YYB-101 (0.1, 0.3, 1, 3, or 10 nм) or human IgG (10 nm; Sigma-Aldrich, St Louis, MO, USA). The cells were washed with ice-cold phosphate-buffered saline (PBS) twice to stop the reaction, lysed in a lysis buffer consisting of $20 \mathrm{~mm}$ Tris ( $\mathrm{pH} 7.4$ ) $137 \mathrm{~mm} \mathrm{NaCl}, 1 \%$ Triton X-100, protease inhibitor cocktail, and phosphatase inhibitor cocktail, and then clarified by centrifugation at $15000 \times g$ for $5 \mathrm{~min}$ at $4{ }^{\circ} \mathrm{C}$. The cell lysate proteins were separated by sodium dodecyl sulfate polyacrylamide gel electrophoresis (NuPAGE 4$12 \%$ Bis-Tris; Invitrogen, Carlsbad, CA, USA) under reducing conditions and transferred to a nitrocellulose membrane, as previously described. ${ }^{17}$ After blocking with 5\% skim milk in PBS containing 0.02\% Tween-20 (blocking buffer) for $30 \mathrm{~min}$, the membranes were incubated overnight at $4{ }^{\circ} \mathrm{C}$ with either an anti-ERK1/2 rabbit antibody (Santa Cruz Biotechnology, Inc., Santa Cruz, CA, USA) or an anti-phospho-ERK1/2 rabbit antibody (Cell Signaling Technology, Inc., Beverly, MA, USA) diluted in blocking buffer (1:1000). The membranes were then incubated with horseradish peroxidase-conjugated mouse anti-rabbit antibody (The Jackson Laboratory, Bar Harbor, ME, USA) diluted in blocking buffer (1:1000) for $1 \mathrm{~h}$ at room temperature. Protein bands were visualized using an enhanced chemiluminescence system (Thermo Fisher Scientific, Waltham, MA, USA) following the manufacturer's instructions.

\section{Scattering assay}

MDCK-2 cells were incubated for $20 \mathrm{~h}$ in Dulbecco's modified Eagle's medium containing $67 \mathrm{pM}$ HGF alone or in combination with either control IgG or YYB-101, as previously reported. ${ }^{15}$ The cells were fixed with $100 \mu \mathrm{l}$ paraformaldehyde (4\%) for $30 \mathrm{~min}$ at room temperature and washed with PBS. Photographs were taken of individual colonies.

\section{Orthotopic mouse model of human glioblastoma}

Human glioblastoma U-87 MG cells were washed, resuspended in PBS, and then injected stereotactically into the left striatum of 6-week-old female Balb/c nude mice $\left(1 \times 10^{5}\right.$ per mouse). The injection coordinates were $2.2 \mathrm{~mm}$ to the left of the midline and $0.2 \mathrm{~mm}$ posterior to the bregma at a depth of $3.5 \mathrm{~mm}$. After 1 week, YYB-101 or control IgG was administered by intraperitoneal injection $\left(5,10\right.$, or $30 \mathrm{mg} \mathrm{kg}^{-1}$; $n=10$ per group) three times per week. TMZ $\left(5 \mathrm{mg} \mathrm{kg}^{-1}\right)$ or $2.5 \%$ cremophor (TMZ control) was administered by oral gavage twice a week. After 3 weeks, the mice were killed, and tumor tissue was collected and immediately frozen in liquid nitrogen. All animal experiments were conducted in accordance with protocols approved by the Institutional Animal Care and Use Committee at the National Cancer Center, Republic of Korea.

\section{Magnetic resonance imaging}

Magnetic resonance imaging (MRI) studies were carried out using a 7.0 T magnet (BioSpin, Bruker, Germany). After localizer imaging on three orthogonal axes, T2-weighted images of the entire mouse brain were acquired using a rapid acquisition with refocused echoes sequence, with TR and TE set to 2500 and $35 \mathrm{~ms}$, respectively. Other parameters used were a $2-\mathrm{cm}$ field of view and a $256 \times 256$ matrix in four averages, resulting in a total scan time of $4 \mathrm{~min}$.

\section{RNA preparation}

Snap-frozen brain tumor tissue of mice bearing human glioblastoma xenografts was pulverized in liquid nitrogen using a frozen mortar and pestle. Total RNA was extracted using TRIzol reagent (Invitrogen) and purified using RNeasy columns (Qiagen, Valencia, CA, USA) according to the manufacturers' protocol.

\section{Microarray}

To generate biotinylated cRNA, total RNA was amplified and purified using the Ambion Illumina RNA amplification kit (Ambion, Austin, TX, USA) according to the manufacturer's instructions. Briefly, total RNA was reverse transcribed using a T7 oligo(dT) primer. Secondstrand cDNA was synthesized, in vitro transcribed, and labeled with biotin-NTP. After purification, the cRNA was quantified using a spectrophotometer (NanoDrop ND-1000, Wilmington, DE, USA). Labeled cRNA samples were hybridized to each HumanHT-12 v4 Expression BeadChip for $16-18 \mathrm{~h}$ at $58^{\circ} \mathrm{C}$, according to the manufacturer's instructions (Illumina, Inc., San Diego, CA, USA). Signal detection was carried out using Amersham Fluorolink Streptavidin-Cy3 (GE Healthcare Bio-Sciences, Little Chalfont, UK), and the arrays were scanned with an Illumina Bead Array Reader confocal scanner according to the manufacturer's instructions. Array data export processing and analysis was performed using Illumina BeadStudio v3.1.3 (Gene Expression Module v3.3.8).

\section{Real-time PCR}

Total RNA $(1 \mu \mathrm{g})$ extracted from brain tumor tissue was used to synthesize cDNA using M-MLV reverse transcriptase (Invitrogen). Real-time PCR assays were performed using a LightCycler 480 SYBR Green I Master reaction mix (Roche Molecular Systems, Pleasanton, CA, USA) and the following gene-specific primers: transmembrane protein 119 (TMEM119) sense 5'-GCCTCCTCATCCTTCTGTTG-3' and antisense $5^{\prime}$-TATCCCATCCAGGAAGTTGG-3'; follistatin (FST), sense $\quad 5^{\prime}$-GTTTTCTGTCCAGGCAGCTCCAC- $3^{\prime}$ and antisense 5'-GCAAGATCCGGAGTGCTTTACT-3'; R-spondin 3 (RSPO3), sense $5^{\prime}$-AATACATCGGCAGCCAAAACGCC- $3^{\prime}$ and antisense $5^{\prime}$-TG TCAAGGCACTTTCCAAGGTG-3'; proto-oncogene tyrosine-protein kinase ROS (ROS1), sense 5'-GGTGACAGTGCTTATAAACG-3' and antisense $5^{\prime}$-AAGGTTGGAATGAGCTGGATA- $3^{\prime}$; neuroblastoma 1 (NBL1), sense 5'-CCAAGTCCATCCAGAACAGG-3' and antisense 5'-CTCAGCCCCCTCTTCCTCT-3'; and glyceraldehyde 3-phosphate dehydrogenase (GAPDH), sense $5^{\prime}$-ACCACAGTCCATGCCATCAC-3' and antisense 5'-TCCACCACCCTGTTGCTGTA-3'. 
a

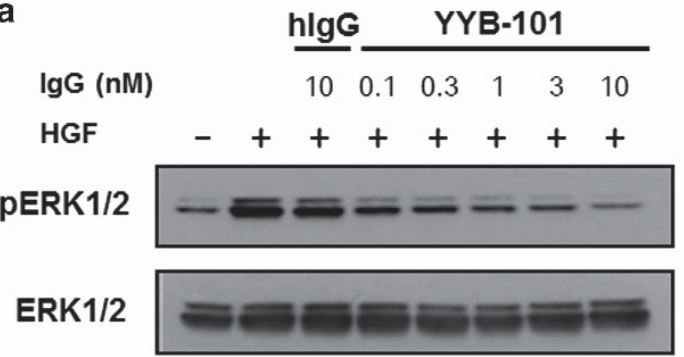

b
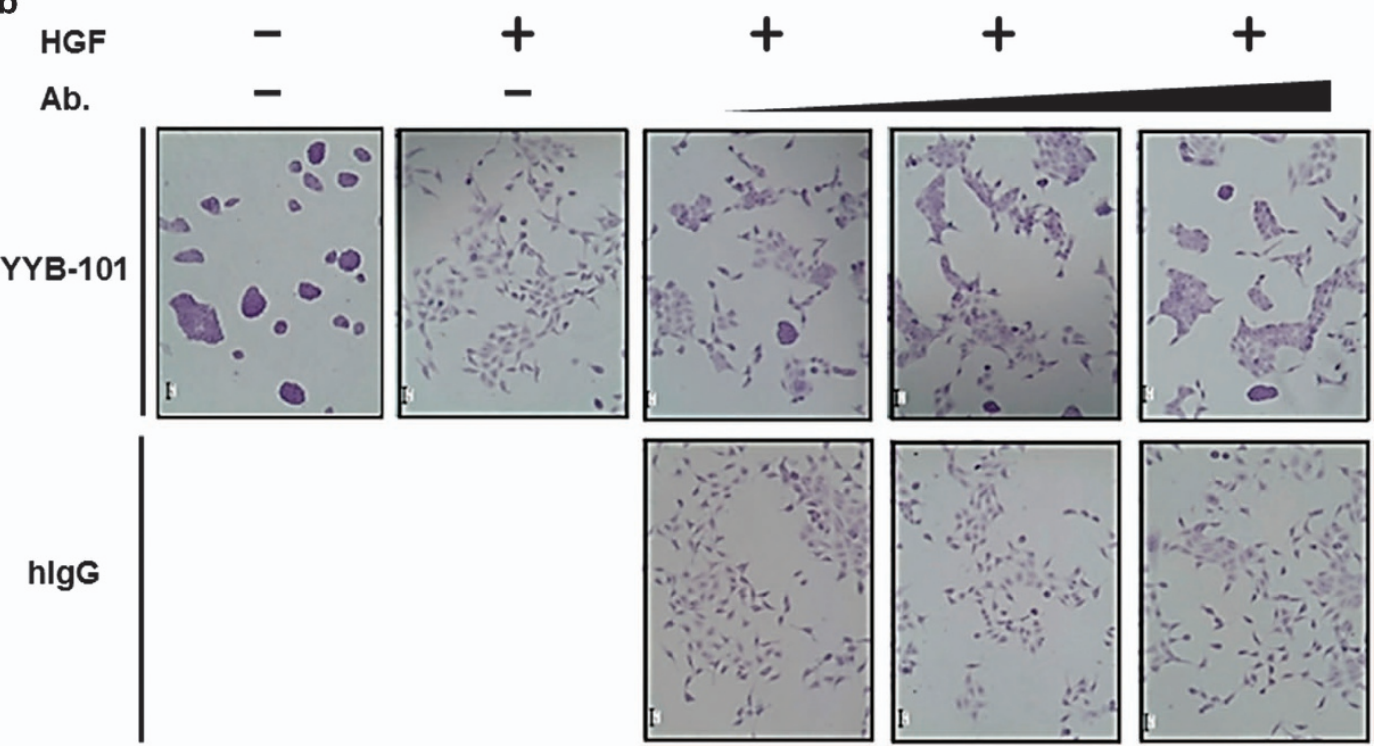

Figure 1 Neutralization of hepatocyte growth factor (HGF) by YYB-101. (a) HepG2 cells were treated with 130 pM HGF alone or in combination with human IgG (hlgG) or YYB-101, and HGF/cMET signaling was evaluated by immunoblot using anti-phosphoERK1/2 and anti-ERK1/2 antibodies. (b) HGF-induced scatter was evaluated by incubating MDCK-2 cells with 67 pM HGF alone or in combination with either hlgG or YYB-101 (1, 10 or $100 \mathrm{nm).}$

\section{Tissue cross-reactivity of YYB-101}

The cross-reactivity of YYB-101 was evaluated in cryosections of 40 different tissue samples from three human donors, kidney and liver tissue samples from nine human donors, and 10 tissue samples from three cynomolgus monkeys. The study was designed to meet the requirements of the US Food and Drug Administration and the European Medicines Agency. In brief, YYB-101 and the control human IgG4 (Abcam, Cambridge, MA, USA) were labeled using the ImmunoProbe Biotinylation Kit (Sigma-Aldrich) according to the manufacturer's instructions. Tissue sections were fixed in acetone and tested with $0.02-10 \mu \mathrm{g} \mathrm{ml}^{-1}$ of biotinylated YYB-101 and biotinylated human IgG4. Three concentrations of biotinylated YYB-101 were selected for antibody titration: $1.25,0.63$ and $0.31 \mu \mathrm{g} \mathrm{ml}^{-1}$. Slides were incubated with either biotinylated YYB-101 or biotinylated human IgG4 diluted in $0.2 \%$ bovine serum albumin at room temperature for $1 \mathrm{~h}$, followed by a 45-min incubation with the secondary biotinylated antibody labeled with peroxidase (Vectastain Elite ABC kit, Vector Laboratories, Burlingame, CA, USA). The tissue sections were then stained with 3,3'-diaminobenzidine tetrahydrochloride (Vector Laboratories) and counterstained with hematoxylin. The intensity of the specific immunohistochemical staining was graded on a scale of $1-5$, where $1=$ negative and $5=$ intense reactivity. Cross-reactivity was reported as the mean score (the sum of the values was divided by the number of tissue samples evaluated).
Pharmacokinetics, toxicokinetics and anti-drug antibodies of YYB-101 in cynomolgus monkeys

This study was conducted by the Test and Control Article Department of Medicilon Preclinical Research, LLC, (Shanghai, China) in accordance with regulations outlined in the USDA Animal Welfare act and conditions specified in The Guide for the Care and Use of Laboratory Animals. ${ }^{18}$ Four male cynomolgus monkeys (3-5 years old), originally obtained from Guangxi Grandforest Scientific Primate Company, Ltd. (Guangxi, China), were used in this study. At study termination, all animals were transferred to the stock colony.

YYB-101 was diluted in buffer containing $20 \mathrm{~mm}$ sodium phosphate, $150 \mathrm{~mm} \mathrm{NaCl} \mathrm{(pH} \mathrm{7.0),} \mathrm{and} 0.01 \%$ Polysorbate 20 (final concentration, $0.6 \mathrm{mg} \mathrm{ml}^{-1}$ ), sterilized using a $0.22-\mu \mathrm{m}$ filter, and then administered via intravenous infusion for $2 \mathrm{~h}$. Blood samples were collected from the femoral vein pre-dose and 2, 4, 8, 24, $48,96,168,240,336,504$ and $672 \mathrm{~h}$ after initiation of the infusion. The blood samples were allowed to clot and then centrifuged at $3500 \mathrm{rpm}$ for $10 \mathrm{~min}$ at $4{ }^{\circ} \mathrm{C}$. The serum was stored at $-80^{\circ} \mathrm{C}$.

The concentration of YYB-101 in the serum samples was determined by using a sandwich enzyme immunoassay. The microtiter plate (Corning, Oneonta, NY, USA) was pre-coated with recombinant human HGF (R\&D Systems, Minneapolis, MN, USA) before adding serum samples and standards to the wells. After incubation and washing, analytes were detected by using horseradish peroxidaseconjugated goat anti-human IgG (kappa chain specific) and the 


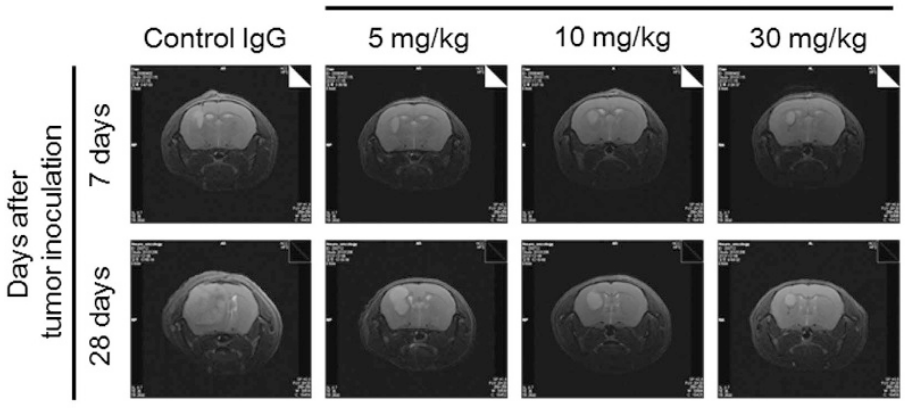

C
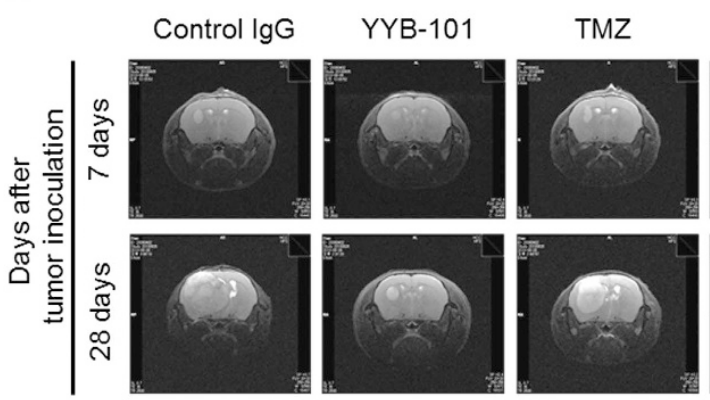

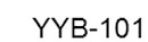
+ TMZ

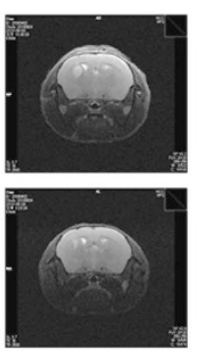

b

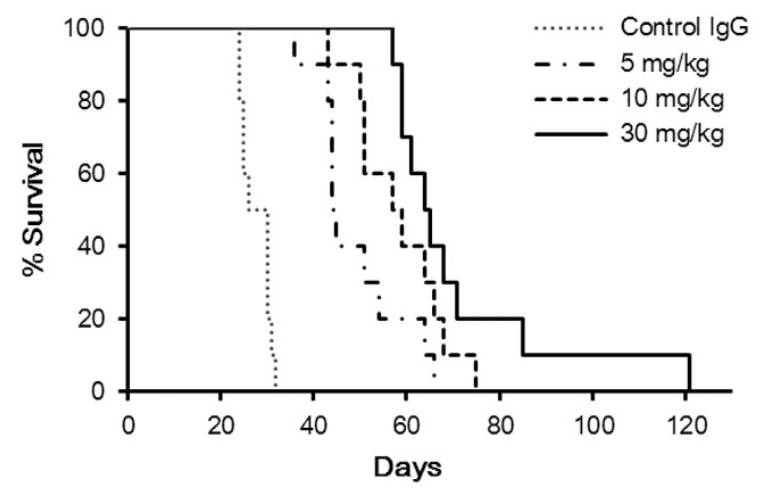

d

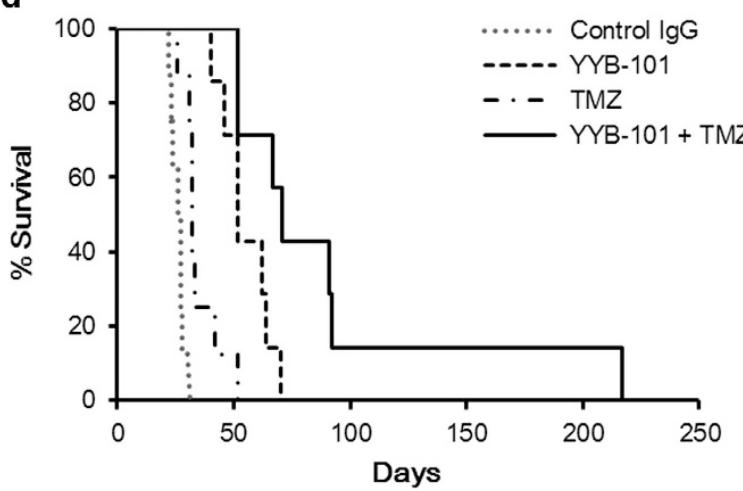

Figure 2 Effect of YYB-101 with or without temozolomide on tumor growth and survival in mice bearing human glioblastoma xenografts. On day 7 after tumor inoculation, the tumor-bearing mice began treatment with lgG (10 mg kg-1) or YYB-101 (5, 10 or 30 mg kg ${ }^{-1}$, $n=10$ per group), which was administered three times per week for 3 weeks. (a) MRI brain scans performed at 7 and 28 days. (b) A Kaplan-Meier curve was constructed, and survival was analyzed by log-rank test (control versus each YYB-101-treated group, $P<0.001 ; 5 \mathrm{mg} \mathrm{kg}^{-1}$ YYB-101 versus $30 \mathrm{mg} \mathrm{kg}^{-1}$ YYB-101, $\left.P=0.0024\right)$. On day 7 after tumor inoculation, the tumor-bearing mice received $10 \mathrm{mg} \mathrm{kg}^{-1} \operatorname{lgG}(n=8), 10 \mathrm{mg} \mathrm{kg}^{-1}$ YYB-101 $(n=7), 5 \mathrm{mg} \mathrm{kg}^{-1}$ temozolomide $(\mathrm{TMZ}, n=8)$, or YYB-101+TMZ $(n=7)$. (c) MRI brain scans were performed at 7 and 28 days. (d) A Kaplan-Meier curve was constructed, and survival was analyzed by log-rank test (control versus TMZ-treated groups, $P=0.005$; TMZ versus combination treatment, $P=0.0001$ ).

substrate o-phenylenediamine (Thermo Fisher Scientific). The enzyme-substrate reaction was terminated by adding $1 \mathrm{~N} \mathrm{H}_{2} \mathrm{SO}_{4}$ solution, and the color change was measured spectrophotometrically at $492 \mathrm{~nm}$. Estimates of non-compartmental pharmacokinetic parameters such as time of maximum observed serum concentration $\left(\mathrm{T}_{\max }\right)$, maximum observed serum concentration $\left(\mathrm{C}_{\max }\right)$, area under the serum concentration-time curve from zero to infinity $\left(\mathrm{AUC}_{0-\infty}\right)$, terminal exponential half-life $\left(\mathrm{t}_{1 / 2 \mathrm{z}}\right)$, and clearance were calculated with WinNolin software (version 5, Pharsight Corporation, Cary, NC, USA).

Blood samples were collected from all surviving animals. On days 1 and 22, blood was obtained before infusion and approximately 2, 4, $8,24,48$, and $96 \mathrm{~h}$ after the start of infusion (SOI). On days 8 and 15, blood was collected before infusion and at approximately $2 \mathrm{~h}$ from the SOI. Blood was also collected once daily on days $29,36,43,57,71$, and 85 (converted to hours relative to SOI on day 22). The samples obtained $2 \mathrm{~h}$ from the SOI were collected within $2 \mathrm{~min}$ prior to the end of infusion. Blood samples were also collected at all time points from control animals; however, only the samples collected $2 \mathrm{~h}$ from the SOI were analyzed. For each animal, the following toxicokinetic parameters were determined: maximum observed serum concentration $\left(\mathrm{C}_{\max }\right)$, time of maximum observed serum concentration $\left(\mathrm{T}_{\max }\right)$, and area under the serum concentration-time curve (AUC). The
AUC from time 0 to $168 \mathrm{~h}\left(\mathrm{AUC}_{0-168 \mathrm{~h}}\right)$ and $\mathrm{AUC}$ from time 0 to the time of the final quantifiable sample $\left(\mathrm{AUC}_{\text {tlast }}\right)$ were calculated by the linear trapezoidal method. ${ }^{19}$ The accumulation ratio $(R)$ was calculated for each dose group as follows:

$$
R=\mathrm{AUC}_{0-168 \mathrm{~h}} \text { Day } 22 \div \mathrm{AUC}_{0-168 \mathrm{~h} \text { Day } 1}
$$

An enzyme immunoassay was used to detect anti-YYB-101 antibodies in the sera of cynomolgus monkeys. Briefly, a streptavidincoated plate (Meso Scale Discovery, Gaithersburg, MD, USA) was blocked with blocking buffer (3\% bovine serum albumin in PBS). HGF mAb master mix containing YYB-101-biotin, YYB-101-SULFOTAG, and assay buffer ( $0.5 \%$ bovine serum albumin, $0.05 \%$ Tween 20 , $0.01 \%$ sodium azide in PBS) was then added to the wells and incubated at room temperature for $30 \mathrm{~min}$. After washing the plate, the samples were added to the wells and incubated at room temperature for $2 \mathrm{~h}$. The plate was washed, $2 \times$ Read Buffer $\mathrm{T}$ (Meso Scale Discovery) was added to the wells, and the plates were read within $20 \mathrm{~min}$.

\section{Serum human HGF levels in a human HGF knock-in transgenic mouse after intravenous injection of YYB-101}

YYB-101 was administered via single intravenous injection $(10,50$, or $200 \mathrm{mg} \mathrm{kg}^{-1}$ ) to $\mathrm{Hg}^{\mathrm{fm} 1.1(\mathrm{HGF}) \text { Aveo }}$ Prkdscid/J mice (Stock \#014543, 

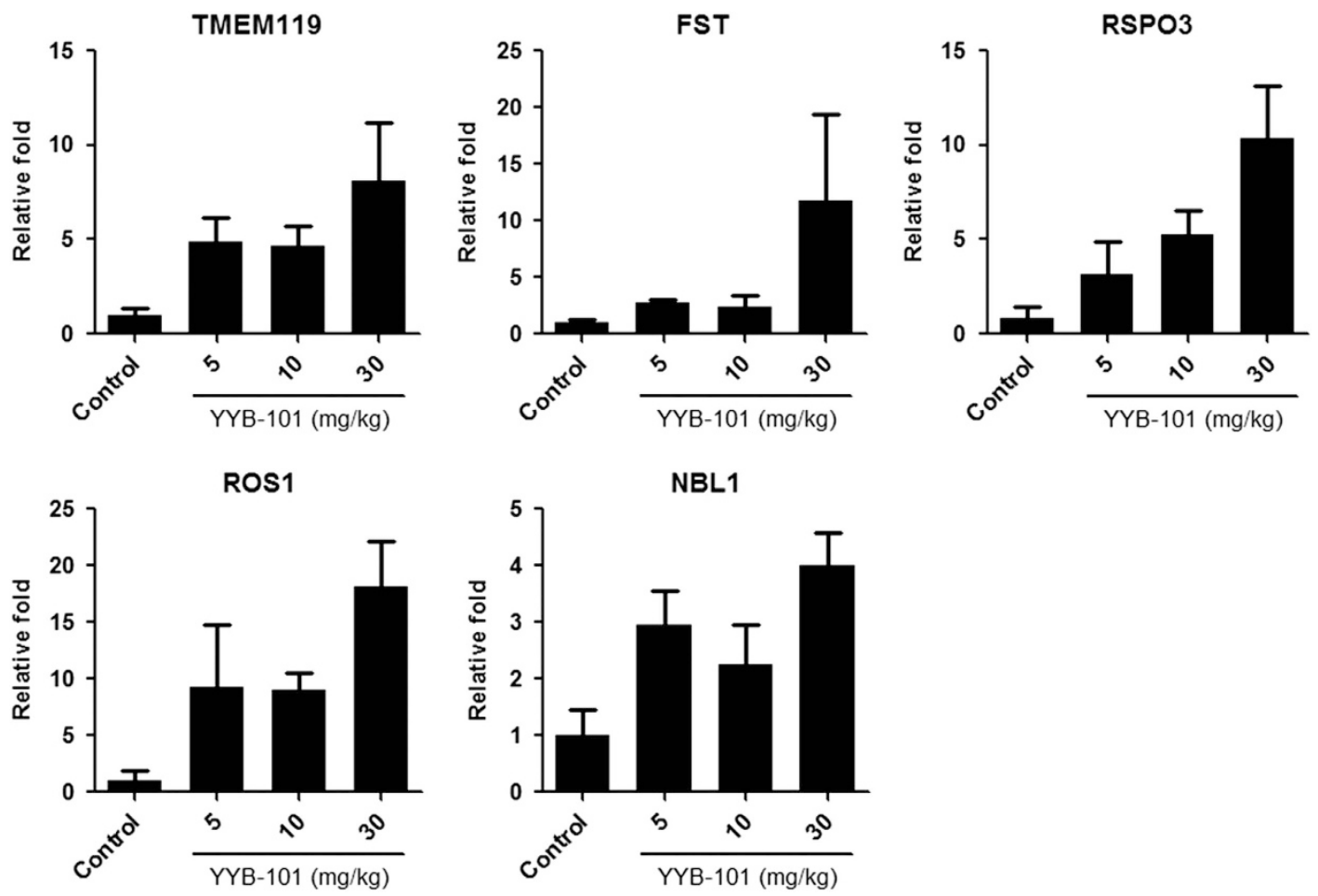

Figure 3 Effect of hepatocyte growth factor (HGF) inhibition on the expression of carcinogenesis-related genes. The relative expression of five carcinogenesis-related genes (TMEM119, FST, RSP03, ROS1 and NBL1) was determined by real-time PCR in tumor tissue of mice treated with $10 \mathrm{mg} \mathrm{kg}^{-1} \mathrm{IgG}$ (control) or 5,10 or $30 \mathrm{mg} \mathrm{kg}^{-1}$ YYB-101 (each group, $n=2$ ). The results are expressed as the mean $\pm \mathrm{S} . \mathrm{d}$. from three independent experiments (control versus each YYB-101-treated group; $P<0.03$ ).

The Jackson Laboratory, Bar Harbor, ME, USA), which possess a knock-in mutation of the human HGF gene. Blood was collected before the injection and $0.5,4,24,48,168,336$ and $504 \mathrm{~h}$ after the injection. Serum was prepared as described earlier. The concentration of human HGF in the serum samples was determined using an enzyme immunoassay kit (Human HGF Quantikine ELISA kit, R\&D Systems, Minneapolis, MN, USA) according to the manufacturer's instructions.

Measurement of serum HGF levels in sarcoma patients This study included 73 patients diagnosed with 22 different sarcomas at Seoul National University Hospital. Blood samples were obtained from September 2013 to July 2015. The serum was separated, aliquoted, and stored at $-80{ }^{\circ} \mathrm{C}$ until analysis. HGF concentrations in the serum were determined using an enzyme-linked immunosorbent assay kit (Human HGF Quantikine ELISA Kit, R\&D Systems) following the manufacturer's instructions.

\section{RESULTS}

Therapeutic efficacy of the HGF neutralizing antibody YYB-101

To evaluate the effect of YYB-101 on HGF/cMET signaling, HepG2 cells were treated with $130 \mathrm{pM}$ HGF along with YYB-101 or IgG. The results of the immunoblot analysis show that YYB-101 decreased ERK1/2 phosphorylation in a dose-dependent manner (Figure 1a). In addition, YYB-101 neutralized the scattering of HGF-treated MDCK-2 cells in a dose-dependent manner, whereas the human IgG control did not show any effect at the same concentrations (Figure 1b).
To determine the efficacy of YYB-101 against tumor growth and survival in vivo, nude mice bearing human glioblastoma xenografts were treated with YYB-101 $\left(5,10\right.$, or $30 \mathrm{mg} \mathrm{kg}^{-1}$; $n=10$ per group) three times a week for 3 weeks. MRI scans of the mouse brain showed that tumor growth was strongly inhibited by YYB-101, and the tumor growth rate negatively correlated with antibody dosage (Figure 2a). Overall survival was longer in YYB-101-treated mice than in IgG-treated control mice $(P<0.0001$; Figure 2b). In consideration of clinical practice, we also tested YYB-101 in combination with TMZ, the standard-of-care chemotherapy drug used for glioblastoma. Our results showed that combination treatment inhibited tumor growth more effectively than YYB-101 alone $(P=0.0164)$ or TMZ alone $(P=0.0001$; Figure 2c) and increased overall survival compared with the survival observed with either agent alone (Figure 2d).

However, as with other treatments, brain tumors treated with YYB-101 eventually showed regrowth. To determine which genes are involved in tumor regrowth, we analyzed microarray data from tumor tissue treated with YYB-101 or IgG (control) and identified 30 genes that were highly expressed in YYB-101-treated tumors compared with expression in controls (Supplementary Table S1). Five of these genes (TMEM119, FST, RSPO3, ROS1 and NBL1) are associated with carcinogenesis. We analyzed the expression of these genes by real-time PCR, which confirmed the microarray data (Figure 3). Our results showed that expression of the carcinogenesis-related genes was 
Table 1 Tissue cross-reactivity of YYB-101

\begin{tabular}{|c|c|c|c|c|c|c|}
\hline & \multicolumn{3}{|c|}{ Human } & \multicolumn{3}{|c|}{ Cynomolgus monkey } \\
\hline & \multicolumn{6}{|c|}{ YYB-101 concentration $\left(\mu \mathrm{g} \mathrm{ml}^{-1}\right)$} \\
\hline & 1.25 & 0.63 & 0.31 & 1.25 & 0.63 & 0.31 \\
\hline Liver $^{a}$ & 1.89 & 1.11 & 0.56 & - & - & - \\
\hline Lung & 1.67 & 1 & 0.67 & - & - & - \\
\hline Breast & 1.67 & 1.67 & 0.67 & - & - & - \\
\hline Colon & 1 & 0.33 & - & - & - & - \\
\hline Heart & 0.33 & - & - & - & - & - \\
\hline Kidneya & 1.33 & 0.78 & 0.56 & - & - & - \\
\hline Prostate & 2.33 & 2 & 1 & - & - & - \\
\hline Urinary bladder & 1.33 & 1 & 0.67 & 0.33 & - & - \\
\hline Pituitary & 2.67 & 2 & 1.67 & - & - & - \\
\hline Placenta & 4 & 3.67 & 2.67 & - & - & - \\
\hline
\end{tabular}

- No positive staining.

aNumber of human donors $=9$.

significantly higher in YYB-101-treated tissue than expression in controls (each comparison, $P<0.03$ ), suggesting the involvement of these genes in tumor regrowth due to YYB-101 resistance.

\section{Cross-reactivity of YYB-101 with human and cynomolgus monkey tissue}

Tissue cross-reactivity studies were assessed in tissue from human donors and cynomolgus monkeys (Table 1). In human tissue, specific staining for YYB-101 was observed in blood vessel walls, epithelial cells, urothelium, connective tissue, stromal tissue, and smooth muscle. In addition, staining for YYB-101 was observed in the brain (Purkinje cells of the cerebellum), lens of the eye, kidney (tubule walls and Bowman's capsule), liver (hepatocytes), and scattered cells in the lung (data not shown).

In the cynomolgus monkey tissue, specific staining for YYB-101 was observed in blood vessel walls within the urinary bladder only. In the 10 tissue samples examined as part of this study, no concordance was observed between humans and cynomolgus monkeys, possibly because of the lower affinity of YYB-101 for monkey HGF (data not shown).

\section{Pharmacokinetics of YYB-101}

The pharmacokinetics of YYB-101 was investigated in four male cynomolgus monkeys after a single intravenous injection $\left(10 \mathrm{mg} \mathrm{kg}^{-1}\right)$. The serum concentration versus time curves and pharmacokinetic parameters of YYB-101 are presented in Figure 4. The YYB-101 serum $\mathrm{T}_{\max }$ was $2 \mathrm{~h}, \mathrm{C}_{\max }$ was $221.57 \mu \mathrm{g} \mathrm{ml}^{-1}$, and $\mathrm{AUC}_{(0-\infty)}$ was $94802.96 \mu \mathrm{g} \mathrm{ml}^{-1} \mathrm{~h}^{-1}$. The $t_{1 / 2 z}$ was $\sim 21.7$ days and clearance was $0.11 \mathrm{ml} \mathrm{kg}^{-1} \mathrm{~h}^{-1}$.

\section{Toxicokinetics of YYB-101 and anti-drug antibodies}

Mean YYB-101 serum concentration-time profiles and toxicokinetic parameters are shown in Table 2. Systemic exposure to YYB-101 was independent of sex (data not shown). Following

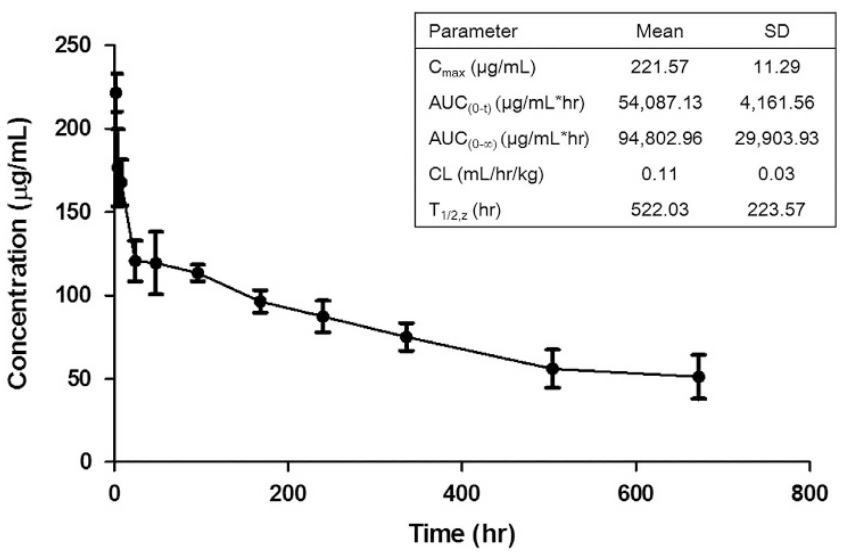

Figure 4 Pharmacokinetic profile of YYB-101 in cynomolgus monkeys. Serum concentration-time curve of YYB-101 in male cynomolgus monkeys following a 2-h intravenous infusion at $10 \mathrm{mg} \mathrm{kg}^{-1}$. The inserted table describes selected pharmacokinetic parameters. The results are expressed as the mean \pm s.d. $(n=3)$.

intravenous administration of YYB-101, the mean systemic exposure $\left(\mathrm{AUC}_{0-168 \mathrm{~h}}\right.$ ) and $\mathrm{C}_{\max }$ values of YYB-101 increased proportionally with dose. The mean peak and trough serum concentrations of YYB-101 appeared to approach steady state following the four weekly infusions of YYB-101 (Table 2). Serum concentrations were quantifiable in recovered animals 63 days after the last dose ( $2.8 \%$ of $\mathrm{C}_{\max }$ from day 22$)$. Systemic exposure $\left(\mathrm{AUC}_{0-168 \mathrm{~h}}\right)$ increased with repeated intravenous administration of YYB-101, with accumulation ratios ranging from 2.38 to 2.95 . Anti-drug antibodies were detected on day 1 in one female monkey at $50 \mathrm{mg} \mathrm{kg}^{-1}$ per day YYB-101 but were not detected in samples collected from this animal on day 29 or 85 . The $C_{\max }$ and AUC values of this animal were similar to those of animals in which no anti-drug antibodies were detected (data not shown).

\section{Changes in serum human HGF levels in the human HGF knock-in mouse}

Because YYB-101 does not bind to mouse HGF, we used human HGF knock-in mice (Hgfml.1(HGF)Aveo Prkds $c^{\text {scid/J) }}$ to evaluate the serum HGF level after injection of YYB-101. In this mouse model, exons $2-18$ of the human HGF gene were inserted into exons 3-6 of the endogenous mouse $H g f$ gene by homologous recombination. The serum HGF concentration was monitored after a single injection of YYB-101 (Figure 5). Before treatment, the mean serum human HGF concentrations were 59, 54, and $71 \mathrm{ng} \mathrm{ml}^{-1}$ in mice treated with the low dose $\left(10 \mathrm{mg} \mathrm{kg}^{-1}\right)$, medium dose $\left(50 \mathrm{mg} \mathrm{kg}^{-1}\right)$, and high dose (200 $\mathrm{m} \mathrm{kg}^{-1}$ ), respectively. The serum human HGF level dropped below $1 \mathrm{ng} \mathrm{ml}^{-1}$ at $30 \mathrm{~min}$ after the injection in each treatment group. Serum HGF levels were still below 50\% of pre-dose values at $48 \mathrm{~h}$ in the low-dose group, $168 \mathrm{~h}$ in the medium-dose group, and $336 \mathrm{~h}$ in the high-dose group. The mean human HGF levels were higher than that of pre-dose values after $168 \mathrm{~h}$ in the low-dose group and after $504 \mathrm{~h}$ in the medium-dose group. 
Table 2 Toxicokinetic parameters on days 1 and 22 following intravenous infusion of YYB-101 at 10, 50, or $200 \mathrm{mg} \mathrm{kg}^{-1}$ perday in cynomolgus monkeys (males and females combined)

\begin{tabular}{|c|c|c|c|c|c|c|c|c|c|c|}
\hline 10 & 22 & $\begin{array}{c}N \\
\text { Mean } \\
\text { s.d. } \\
\text { CV\% } \\
N \\
\text { Mean } \\
\text { s.d. } \\
\text { cV\% }\end{array}$ & $\begin{array}{c}6 \\
363000 \\
24200 \\
7 \\
6 \\
738000 \\
44300 \\
6\end{array}$ & $\begin{array}{c}6 \\
36300 \\
2420 \\
7 \\
6 \\
73800 \\
4430 \\
6\end{array}$ & $2(2-2)$ & 168 (168-168) & $\begin{array}{c}6 \\
31000000 \\
2980000 \\
10 \\
6 \\
77200000 \\
10700000 \\
14\end{array}$ & $\begin{array}{c}6 \\
31000000 \\
2980000 \\
10 \\
6 \\
77200000 \\
10700000 \\
14\end{array}$ & $\begin{array}{c}6 \\
3100000 \\
298000 \\
10 \\
6 \\
7720000 \\
1070000 \\
14\end{array}$ & $\begin{array}{c}\text { NA } \\
\text { NA } \\
\text { NA } \\
\text { NA } \\
6 \\
2.49 \\
0.286 \\
11\end{array}$ \\
\hline 50 & 22 & $\begin{array}{c}N \\
\text { Mean } \\
\text { s.d. } \\
\text { cv\% } \\
N \\
\text { Mean } \\
\text { s.d. } \\
\text { cv\% }\end{array}$ & $\begin{array}{c}6 \\
1950000 \\
289000 \\
15 \\
6 \\
3650000 \\
75200 \\
2\end{array}$ & $\begin{array}{c}6 \\
39000 \\
5770 \\
15 \\
6 \\
73000 \\
1500 \\
2\end{array}$ & $2(2-2)$ & $168(168-168)$ & $\begin{array}{c}6 \\
163000000 \\
13100000 \\
8 \\
6 \\
387000000 \\
34800000 \\
9\end{array}$ & $\begin{array}{c}6 \\
163000000 \\
13100000 \\
8 \\
6 \\
387000000 \\
34800000 \\
9\end{array}$ & $\begin{array}{c}6 \\
3250000 \\
262000 \\
8 \\
6 \\
7730000 \\
696000 \\
9\end{array}$ & $\begin{array}{l}\text { NA } \\
\text { NA } \\
\text { NA } \\
\text { NA } \\
6 \\
2.38 \\
0.119 \\
5\end{array}$ \\
\hline
\end{tabular}

Abbreviations: AUC, area under the curve; CV, coefficient of variation; NA, not applicable.

a Median (minimum - maximum), median value only reported if actual collection interval.

${ }^{\mathrm{b}} R=\mathrm{AUC}_{0-168 \text { h Day } 22} / \mathrm{AUC}_{0-168 \text { h Day } 1 .}$

\section{Serum HGF level in cancer patients}

The distribution of serum HGF level of the 73 patients included in this study was shown in Figure 6. The median serum HGF level was $1158 \mathrm{pg} / \mathrm{ml}$ (range, 477-13 474), which was considerably greater than the serum HGF level in a normal population (260-390 $\left.\mathrm{pg} \mathrm{ml}^{-1}\right) .{ }^{20}$ The most common sarcoma was osteosarcoma $(n=18)$, and the median serum HGF level in these patients was $1223 \mathrm{pg} \mathrm{ml}^{-1}$ (range, 692-13 474).

\section{DISCUSSION}

Dysregulated HGF-cMET signaling promotes cell survival, proliferation, and invasion. High HGF levels are detected in the serum and tumor tissue of patients with various cancers and are correlated with poor prognosis. Thus, HGF is considered a promising target for cancer therapy, and several HGF inhibitors have been evaluated in clinical studies. Rilotumumab, a fully human anti-HGF antibody, is the most extensively tested HGF inhibitor; however, two phase III clinical studies were halted because of patient deaths. ${ }^{21}$ Clinical trials of combination treatment with the humanized anti-HGF antibody ficlatuzumab and gefitinib in pulmonary adenocarcinoma patients failed to show better efficacy than gefitinib monotherapy. ${ }^{22}$ The results of a phase I study of the humanized anti-HGF antibody HuL2G7 in patients with advanced solid malignancies showed some adverse events but no dose-limiting toxicities. ${ }^{23}$ To date, none of these HGF neutralizing antibodies have shown efficacy in a clinical setting; therefore, we investigated YYB-101 as a potential therapeutic agent.

In this study, we showed that YYB-101 inhibits cMET activation and cell scattering in vitro and suppresses tumor growth in mice bearing human glioblastoma xenografts, which is consistent with results in mouse models of colorectal cancer. ${ }^{23}$ In addition, combination treatment with YYB-101 and TMZ in our study and with irinotecan in the colorectal cancer model was more effective than treatment with YYB-101 alone. We also identified genes that were overexpressed after tumor relapse in the mouse xenograft model, which may be useful in the selection of patients who would be more likely to benefit from YYB-101 treatment.

Rilotumumab binds the beta chain of HGF, which binds cMET with low affinity, leaving the alpha chain free to engage cMET, resulting in partial antagonism. ${ }^{24}$ In contrast, YYB-101 binds to the alpha chain of HGF (manuscript under preparation), which binds cMET with high affinity. ${ }^{25}$ For this reason, YYB-101 may completely block HGF binding to cMET and be more effective in a clinical setting. One of the unique findings of this study was the rapid decrease in serum HGF levels in human HGF knock-in mice, which recovered in a dosedependent manner. In contrast, injection of rilotumumab increased the total plasma level of HGF (free HGF and HGF bound to rilotumumab). ${ }^{26} \mathrm{We}$ discovered that YYB-101 competes with one of the antibodies used in the sandwich enzyme immunoassay. Although it is not clear whether the total HGF level was decreased by YYB-101 injection, the amount of HGF free to bind cMET was reduced.

A recent study reported that serum HGF level is a biomarker that can predict the outcome and resistance to treatment with trastuzumab in HER2-positive patients with metastatic gastric cancer. ${ }^{27}$ Our result that YYB-101 can markedly decrease serum HGF level suggests that the combination of trastuzumab and YYB-101 may provide clinical benefit in these patients. Similarly, 

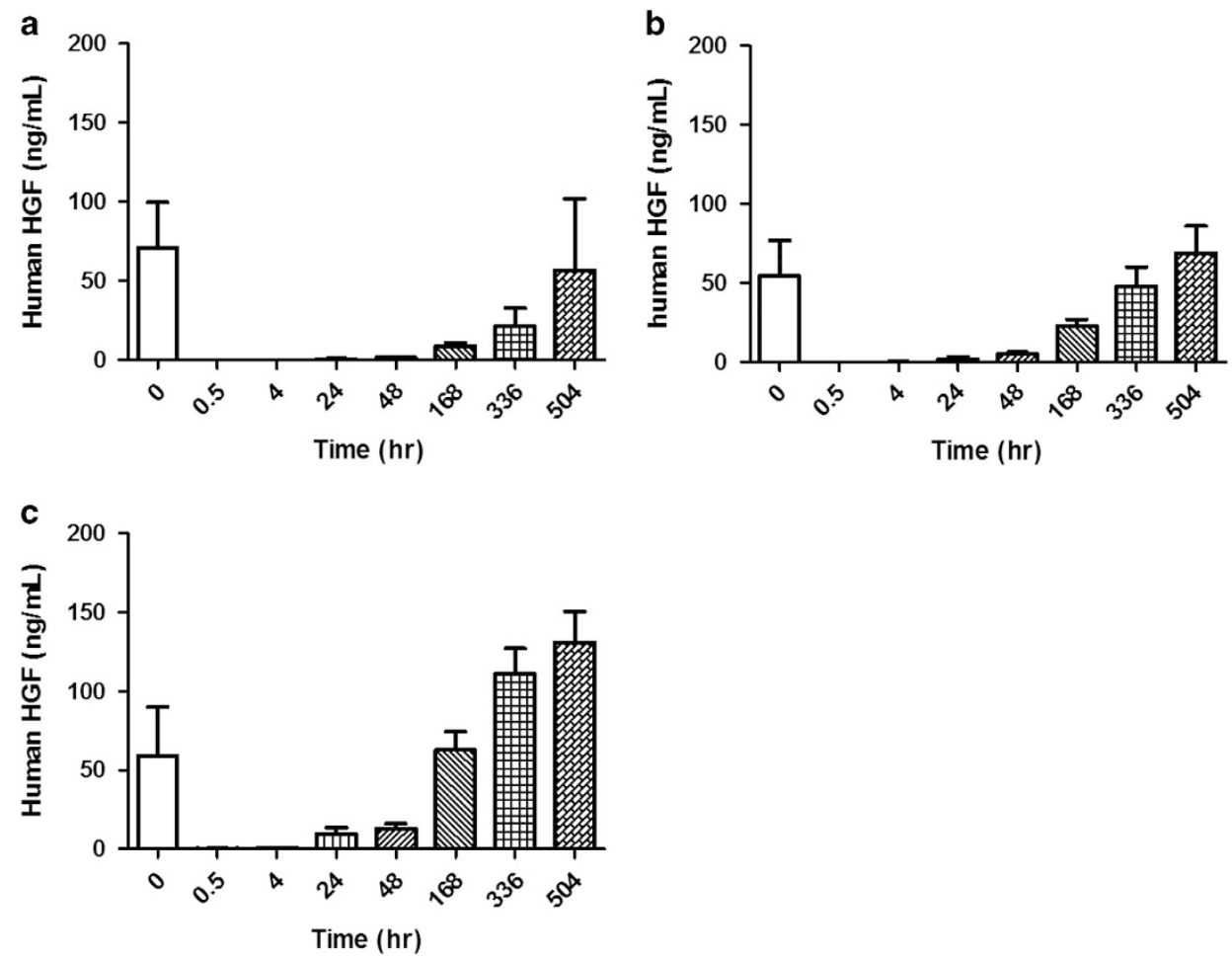

Figure 5 Serum hepatocyte growth factor (HGF) concentration after a single intravenous bolus dose of YYB-101 in human HGF knock-in SCID mice. The mice were treated with (a) $200 \mathrm{mg} \mathrm{kg}^{-1}$ YYB-101, (b) $50 \mathrm{mg} \mathrm{kg}^{-1}$ YYB-101, or (c) $10 \mathrm{mg} \mathrm{kg}-1$ YYB-101. Results are expressed as the mean and \pm s.d. (each group, $n=5$ ).

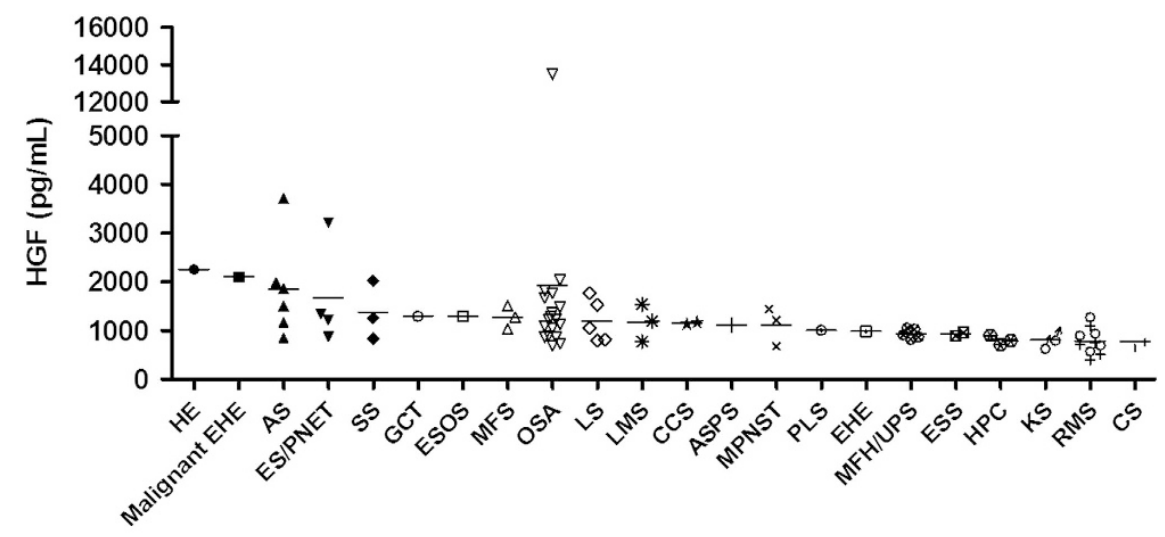

Types of sarcoma

Figure 6 Serum concentration of HGF in sarcoma patients. Each point represents an individual patient, and horizontal lines represent mean values. AS, angiosarcoma; ASPS, alveolar soft part sarcoma; CCS, clear cell sarcoma; CS, chondrosarcoma; EHE, epithelioid hemangioendothelioma; ES/PNET, Ewing sarcoma/primitive neuroectodermal tumor; ESOS, extraskeletal osteosarcoma; ; ESS, endometrial stromal sarcoma GCT, giant cell tumor; HE, hemangioendothelioma; HPC, hemangiopericytoma; KS, Kaposi sarcoma; LMS, leiomyosarcoma; LS, liposarcoma; MFH/UPS, malignant fibrous histiocytoma/pleomorphic undifferentiated sarcoma; MFS, myxofibrosarcoma; MPNST, malignant peripheral nerve sheath tumor; OSA, osteosarcoma; PLS, pleomorphic liposarcoma; RMS, rhabdomyosarcoma; SS, synovial sarcoma.

YYB-101 may be useful in the treatment of ovarian cancer given that an increased serum HGF level is a marker for poor prognosis in this disease, ${ }^{9}$ and the peritoneal spreading of ovarian cancer is enhanced by ascites-mediated activation of cMET. ${ }^{28,29}$

There were no unusual findings regarding the pharmacokinetic and toxicokinetic properties of YYB-101 in cynomolgus monkeys. The peak serum concentration of YYB-101 was observed at $2 \mathrm{~h}$ after infusion, followed by a steep decrease until $24 \mathrm{~h}$ and then a slow elimination, which is comparable to that of other clinically approved antibodies. Anti-drug antibodies were detected in only one animal at a single time point, and little cross-reactivity to normal tissue was observed. On the basis of these results, a phase I clinical study is ongoing in patients with advanced solid tumors (NCT02499224). 


\section{CONFLICT OF INTEREST}

The authors declare no conflict of interest.

\section{ACKNOWLEDGEMENTS}

This study was supported by the National OncoVenture Program (No. HI11C1191) and research grants from the National Cancer Center Grants (NCC0911670 and NCC1111370). The study protocol was approved by the Institutional Review Board of Seoul National University Hospital (H1412-040-632). Written informed consent was obtained from all patients in accordance with the Declaration of Helsinki.

1 Lokker NA, Mark MR, Luis EA, Bennett GL, Robbins KA, Baker JB et al. Structure-Function Analysis of Hepatocyte Growth-Factor-Identification of Variants That Lack Mitogenic Activity yet Retain High-Affinity Receptor-Binding. EMBO J 1992; 11: 2503-2510.

2 Trusolino L, Comoglio PM. Scatter-factor and semaphorin receptors: cell signalling for invasive growth. Nat Rev Cancer 2002; 2: 289-300.

3 Gherardi E, Birchmeier W, Birchmeier C, Vande Woude G. Targeting MET in cancer: rationale and progress. Nat Rev Cancer 2012; 12: 89-103.

4 Singh-Kaw P, Zarnegar R, Siegfried JM. Stimulatory effects of hepatocyte growth factor on normal and neoplastic human bronchial epithelial cells. Am J Physiol 1995; 268(6 Pt 1): L1012-L1020.

5 Zhang YW, Vande Woude GF. HGF/SF-met signaling in the control of branching morphogenesis and invasion. J Cell Biochem 2003; 88: 408-417.

6 Maulik G, Shrikhande A, Kijima T, Ma PC, Morrison PT, Salgia R. Role of the hepatocyte growth factor receptor, c-Met, in oncogenesis and potential for therapeutic inhibition. Cytokine Growth Factor Rev 2002; 13 : 41-59.

7 Birchmeier C, Birchmeier W, Gherardi E, Vande Woude GF. Met, metastasis, motility and more. Nat Rev Mol Cell Biol 2003; 4: 915-925.

8 Christensen JG, Burrows J, Salgia R. C-Met as a target for human cancer and characterization of inhibitors for therapeutic intervention. Cancer Lett 2005; 225: 1-26.

9 Aune G, Lian AM, Tingulstad S, Torp SH, Forsmo S, Reseland JE et al. Increased circulating hepatocyte growth factor (HGF): a marker of epithelial ovarian cancer and an indicator of poor prognosis. Gynecol Oncol 2011; 121: 402-406.

10 Edakuni G, Sasatomi E, Satoh T, Tokunaga O, Miyazaki K. Expression of the hepatocyte growth factor/c-Met pathway is increased at the cancer front in breast carcinoma. Pathol Int 2001; 51: 172-178.

11 Yamashita J, Ogawa M, Yamashita S, Nomura K, Kuramoto M, Saishoji T et al. Immunoreactive hepatocyte growth factor is a strong and independent predictor of recurrence and survival in human breast cancer. Cancer Res 1994; 54: 1630-1633.

12 Maemura M, lino Y, Yokoe T, Horiguchi J, Takei H, Koibuchi Y et al. Serum concentration of hepatocyte growth factor in patients with metastatic breast cancer. Cancer Lett 1998; 126: 215-220.

13 Siegfried JM, Weissfeld LA, Singh-Kaw P, Weyant RJ, Testa JR, Landreneau RJ. Association of immunoreactive hepatocyte growth factor with poor survival in resectable non-small cell lung cancer. Cancer Res 1997; 57: 433-439.

14 Kasahara K, Arao T, Sakai K, Matsumoto K, Sakai A, Kimura H et al. Impact of serum hepatocyte growth factor on treatment response to epidermal growth factor receptor tyrosine kinase inhibitors in patients with non-small cell lung adenocarcinoma. Clin Cancer Res 2010; 16: 4616-4624.

15 Kim K, Hur Y, Ryu EK, Rhim JH, Choi CY, Baek CM et al. A neutralizable epitope is induced on HGF upon its interaction with its receptor cMet. Biochem Biophys Res Commun 2007; 354: 115-121.
16 Woo JK, Kang JH, Kim B, Park BH, Shin KJ, Song SW et al. Humanized anti-hepatocyte growth factor (HGF) antibody suppresses innate irinotecan (CPT-11) resistance induced by fibroblast-derived HGF. Oncotarget 2015; 6: 24047-24060.

17 Burnette WN. 'Western blotting': electrophoretic transfer of proteins from sodium dodecyl sulfate-polyacrylamide gels to unmodified nitrocellulose and radiographic detection with antibody and radioiodinated protein A. Anal Biochem 1981; 112: 195-203.

18 Institute of Laboratory Animal Research CoLS, National Research Council Guide for the Care and Use of Laboratory Animals. National Academy Press: Washington, DC, USA, 1996.

19 M. Gibaldi DP. Pharmacokinetics, 2nd edn, Taylor \& Francis: Oxfordshire, UK, 1982.

20 Funakoshi $\mathrm{H}$, Nakamura T. Hepatocyte growth factor: from diagnosis to clinical applications. Clin Chim Acta 2003; 327: 1-23.

21 Cunningham DTN, Davidenko I, Murad AM. Phase III, randomized, doubleblind, multicenter, placebo $(P)$-controlled trial of rilotumumab $(R)$ plus epirubicin, cisplatin and capecitabine (ECX) as first-line therapy in patients (pts) with advanced MET-positive (pos) gastric or gastroesophageal junction (G/GEJ) cancer: RILOMET-1 study. J Clin Oncol 2015; 33 (suppl;abstr 4000).

22 Mok TS, Geater SL, Su WC, Tan EH, Yang JC, Chang GC et al. A randomized phase 2 Study comparing the combination of ficlatuzumab and gefitinib with gefitinib alone in Asian patients with advanced stage pulmonary adenocarcinoma. J Thorac Oncol 2016; 11: $1736-1744$

23 Woo JK, Kang JH, Kim B, Park BH, Shin KJ, Song SW et al. Humanized anti-hepatocyte growth factor (HGF) antibody suppresses innate irinotecan (CPT-11) resistance induced by fibroblast-derived HGF. Oncotarget 2015; 6: 24047-24060

24 Greenall SA, Adams TE, Johns TG. Incomplete target neutralization by the anti-cancer antibody rilotumumab. MAbs 2016; 8: 246-252.

25 Kirchhofer D, Yao X, Peek M, Eigenbrot C, Lipari MT, Billeci KL et al. Structural and functional basis of the serine protease-like hepatocyte growth factor beta-chain in Met binding and signaling. $\mathrm{J}$ Biol Chem 2004; 279: 39915-39924.

26 Zhang Y, Doshi S, Zhu M. Pharmacokinetics and pharmacodynamics of rilotumumab: a decade of experience in preclinical and clinical cancer research. Br J Clin Pharmacol 2015; 80: 957-964.

27 Rimassa L, Abbadessa G, Personeni N, Porta C, Borbath I, Daniele B et al. Tumor and circulating biomarkers in patients with second-line hepatocelIular carcinoma from the randomized phase II study with tivantinib. Oncotarget 2016; 7: 72622-72633.

28 Nakamura M, Ono YJ, Kanemura M, Tanaka T, Hayashi M, Terai Y et al. Hepatocyte growth factor secreted by ovarian cancer cells stimulates peritoneal implantation via the mesothelial-mesenchymal transition of the peritoneum. Gynecol Oncol 2015; 139: 345-354.

29 Matte I, Lane D, Laplante C, Garde-Granger P, Rancourt C, Piche A Ovarian cancer ascites enhance the migration of patient-derived peritoneal mesothelial cells via cMet pathway through HGF-dependent and -independent mechanisms. Int J Cancer 2015; 137: 289-298.

This work is licensed under a Creative Commons Attribution-NonCommercial-NoDerivs 4.0 Interint this article are included in the article's Creative Commons license, unless indicated otherwise in the credit line; if the material is not included under the Creative Commons license, users will need to obtain permission from the license holder to reproduce the material. To view a copy of this license, visit http://creativecommons.org/licenses/by-nc-nd/4.0/

Supplementary Information accompanies the paper on Experimental \& Molecular Medicine website (http://www.nature.com/emm) 